\title{
Water-Intake and Water-Molecule Paths to the Active Site of Secretory Phospholipase A2 Studied Using MD Simulations and the Tracking Tool AQUA-DUCT
}

\author{
Tjørnelund, Helena D.; Madsen, Jesper J.; Peters, Günther H.J.
}

Published in:

Journal of Physical Chemistry Part B: Condensed Matter, Materials, Surfaces, Interfaces \& Biophysical

Link to article, DOI:

10.1021/acs.jpcb.9b10837

Publication date:

2020

Document Version

Publisher's PDF, also known as Version of record

Link back to DTU Orbit

Citation (APA):

Tjørnelund, H. D., Madsen, J. J., \& Peters, G. H. J. (2020). Water-Intake and Water-Molecule Paths to the Active Site of Secretory Phospholipase A2 Studied Using MD Simulations and the Tracking Tool AQUA-DUCT. Journal of Physical Chemistry Part B: Condensed Matter, Materials, Surfaces, Interfaces \& Biophysical, 124(10), 18811891. https://doi.org/10.1021/acs.jpcb.9b10837

\section{General rights}

Copyright and moral rights for the publications made accessible in the public portal are retained by the authors and/or other copyright owners and it is a condition of accessing publications that users recognise and abide by the legal requirements associated with these rights.

- Users may download and print one copy of any publication from the public portal for the purpose of private study or research.

- You may not further distribute the material or use it for any profit-making activity or commercial gain

- You may freely distribute the URL identifying the publication in the public portal 


\title{
Water-Intake and Water-Molecule Paths to the Active Site of Secretory Phospholipase $A_{2}$ Studied Using MD Simulations and the Tracking Tool AQUA-DUCT
}

\author{
Helena D. Tjørnelund, Jesper J. Madsen, and Günther H. J. Peters*
}

Cite This: J. Phys. Chem. B 2020, 124, 1881-1891

Read Online

ACCESS

Џll Metrics \& More

回国 Article Recommendations

S1 Supporting Information

ABSTRACT: Secretory phospholipases $\mathrm{A}_{2}\left(\mathrm{sPLA}_{2} \mathrm{~s}\right)$ are a subclass of enzymes that catalyze the hydrolysis at the sn-2 position of glycerophospholipids, producing free fatty acids and lysophospholipids. In this study, different phospholipids with structural modifications close to the scissile sn-2 ester bond were studied to determine the effect of the structural changes on the formation of the Michaelis-Menten complex and the water entry/exit pathways using molecular dynamics simulations and the computational tracking tool AQUA-DUCT. Structural modifications include methylation, dehydrogenation, and polarization close to the sn-2 scissile bond. We found that all water molecules reaching the active site of sPLA -IIA pass by the aromatic residues $\mathrm{Phe}^{5}$ and $\mathrm{Tyr}^{51}$ and enter the active site

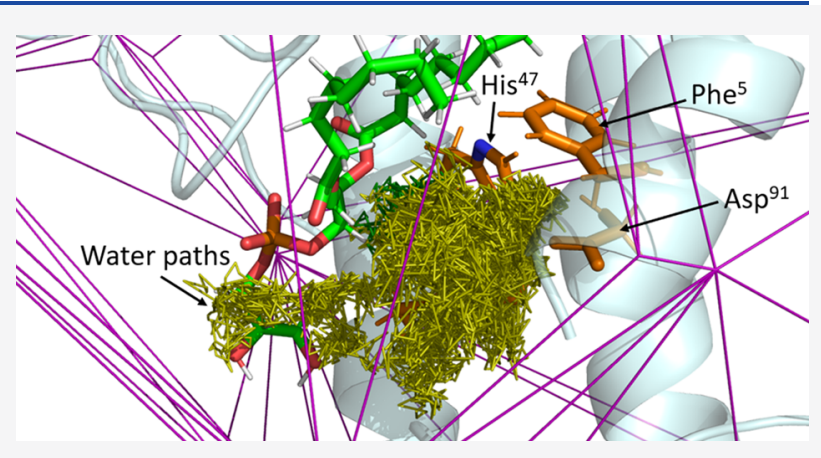
through an active-site cleft. The relative amount of water available for the enzymatic reaction of the different phospholipid-sPLA 2 complexes was determined together with the distance between key atoms in the catalytic machinery. The results showed that $(Z)$ unsaturated phospholipid is a good substrate for $\mathrm{SPLA}_{2}$-IIA. The computational results are in good agreement with previously reported experimental data on the ability of $\mathrm{sPLA}_{2}$-IIA to hydrolyze liposomes made from the different phospholipids, and the results provide new insights into the necessary active-site solvation of the Michaelis-Menten complex and can pave the road for rational design in engineering applications.

\section{INTRODUCTION}

Phospholipases $\mathrm{A}_{2}\left(\mathrm{PLA}_{2} \mathrm{~s}\right)$ form a diverse class of hydrolytic enzymes that are responsible for synthesizing intracellular messengers and remodeling of cellular phospholipids. ${ }^{1-3}$ Lipolytic $\mathrm{PLA}_{2} \mathrm{~S}$ cleave the sn-2 acyl ester bond of glycerophospholipids, producing free fatty acids and lysophospholipids. ${ }^{4-6}$ The superfamily comprising $\mathrm{PLA}_{2} \mathrm{~S}$ is classified into six main groups based on their biochemical properties such as calcium dependency, primary structure, subcellular location, molecular weight, and amino acid similarities. ${ }^{4,7}$ These are the high-molecular-weight cytosolic $\mathrm{PLA}_{2}\left(\mathrm{cPLA}_{2}\right)$, the low-molecular-weight secretory $\operatorname{PLA}_{2}\left(\operatorname{sPLA}_{2}\right)$, the calcium-independent $\mathrm{PLA}_{2}\left(\mathrm{iPLA}_{2}\right)$, the platelet-activating factor acetylhydrolases (PAF-AH), the lysosomal PLA $\left(\mathrm{LyPLA}_{2}\right)$, and the adipose-specific $\operatorname{PLA}_{2}\left(\mathrm{AdPLA}_{2}\right){ }^{8-10}$ $\mathrm{PLA}_{2} \mathrm{~s}$ and particularly $\mathrm{sPLA}_{2} \mathrm{~s}$ have drawn much attention since they are therapeutic targets for treating inflammatory and oncologic diseases. ${ }^{11}$ The subclass sPLA $_{2}$ consists of small secreted enzymes with molecular weights of around 14-19 $\mathrm{kDa}$. The enzymes have a high content of disulfide bonds and need calcium ions to catalyze the hydrolysis of phospholipids. $8,9,12$ They have a broad specificity toward different phospholipids with varying headgroups, ${ }^{12}$ and since they are surface-active enzymes, the microstructure and physical state of a cell membrane surface affect the affinity and activity of sPLA $_{2} \cdot{ }^{13,14}$ sPLA $_{2}$ group II enzymes including sPLA - -IIA have been targeted because of their implementation in different physiological processes. ${ }^{14,15}$ sPLA $_{2}$-IIA primarily shows affinity toward membranes containing anionic phospholipids, such as Gram-positive bacteria, while it does not degrade membranes built of zwitterionic lipids, such as the membrane of mammalian cells. ${ }^{2,14,16,17}$ This selectivity is caused by electro-

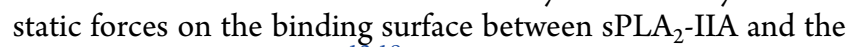
phospholipid membrane. ${ }^{13,18}$ Many sPLA 2 s can degrade both anionic and zwitterionic lipids; an example is $\mathrm{sPLA}_{2}$ found in snake venom, which lacks the cationic residues that in human sPLA $_{2}$-IIA facilitate binding of the enzyme to a negatively charged phospholipid membrane. ${ }^{19,20}$ sPLA $_{2}$-IIA is expressed in inflammatory tissues, and more interesting elevated levels of sPLA $_{2}$-IIA are present in certain cancer tissues such as breast, ${ }^{21}$ prostate, $^{22,23}$ colon, $^{24}$ and pancreatic cancer. ${ }^{25}$ This indicates

Received: November 19, 2019

Revised: February 11, 2020

Published: February 17, 2020 
that $\mathrm{SPLA}_{2}$-IIA has a key function in the development and progression of cancer, which makes the enzyme a target for novel, site-specific anticancer drug delivery systems in the form of liposomes. $^{26,27}$ The anticancer drug would be inside the liposome, and when the liposome membrane is degraded by sPLA 2 -IIA hydrolysis of the lipids, the anticancer drug is released. Furthermore, the hydrolysis products, i.e., the free fatty acid and the lysophospholipid, enhance the permeability of the membrane and hence the cancer cell uptake of the anticancer drug. $^{27,28}$ The liposomal drug delivery systems can be designed by modifying the sn- 1 or sn- 2 chains of the phospholipids to optimize the stability of liposomes and the release profile of anticancer drugs. ${ }^{26}$ It has previously been presented that unnatural phospholipids with the headgroup positioned at sn- 2 instead of sn- 3 can form stable liposomes, which are still degradable by SPLA $_{2}$-IIA, albeit at a lower activity when compared to the natural substrate. ${ }^{29}$ Furthermore, it has also been shown that phospholipids with sn-1 substitutions can be hydrolyzed by sPLA $_{2}$-IIA as long as substitutions in the sn-1 chain do not affect the flow of water molecules to the active site. ${ }^{30}$

Our study was motivated by an experimental study that investigated the $\mathrm{sPLA}_{2}$-IIA activity toward phospholipids structurally modified close to the scissile ester bond located in the sn-2 fatty acid chain (hereafter, referred to as $s n-2^{\mathrm{seb}}$ ). The authors assessed the enzyme activity toward the different phospholipids by quantifying substrate depletion and product formation using matrix-assisted laser desorption ionizationtime-of-flight mass spectrometry (MALDI-TOF-MS) and high-performance liquid chromatography (HPLC). ${ }^{31}$ The aim of this study was to investigate how these structural modifications in phospholipids close to $\mathrm{sn}-2^{\text {seb }}$ affect the formation of the Michaelis-Menten complex and the water intake. The former involves monitoring of key distances in the Michaelis-Menten complexes for different phospholipid analogue-sPLA $\mathrm{S}_{2}$-IIA complexes. The latter focusses on determining the water-intake and the water-molecule path to the active site in $\mathrm{SPLA}_{2}$-IIA using the tracking tool AQUADUCT (version 0.5.14). ${ }^{32}$ This tracking tool has previously been successfully used to study the water-molecule path into the active site of $\mathrm{D}$-amino acid oxidase. ${ }^{33}$ In light of this study, 11 different $\mathrm{sPLA}_{2}-$ phospholipid complexes were studied using molecular dynamics (MD) simulations, and the resulting trajectories were analyzed with regard to the water-molecule movements. The different phospholipids were the natural substrate for $\mathrm{SPLA}_{2}$-IIA and 10 analogues, whose chemical structures are shown in Figure 1. The natural substrate will from here on be referred to as the saturated substrate/ phospholipid. The 10 analogues all have saturated sn- 1 chains, and the differences in the analogues are placed close to $s n-2^{\text {seb }}$. The analogues were designed to investigate the effect of dehydrogenation, methylation, and electronic polarization (fluorinated analogues) close to sn- $2^{\text {seb }}$ on the enzyme activity and water-molecule path toward the active site. Our computational results revealed that the structural integrity of the phospholipid close to $s n-2^{\text {seb }}$ is essential for the phospholipid to be a substrate for sPLA 2 -IIA, and the results are in good agreement with experimental results. ${ }^{31}$ We find that several residues conserved across different $\mathrm{SLA}_{2}$ species are involved in directing water molecules to the active-site region. These residues are the surface-exposed residues $\mathrm{Asn}^{1}, \mathrm{Leu}^{2}, \mathrm{Thr}^{61}$, and $\mathrm{Lys}^{62}$ and the conserved aromatic residues, $\mathrm{Phe}^{5}$ and $\mathrm{Tyr}^{51}$,

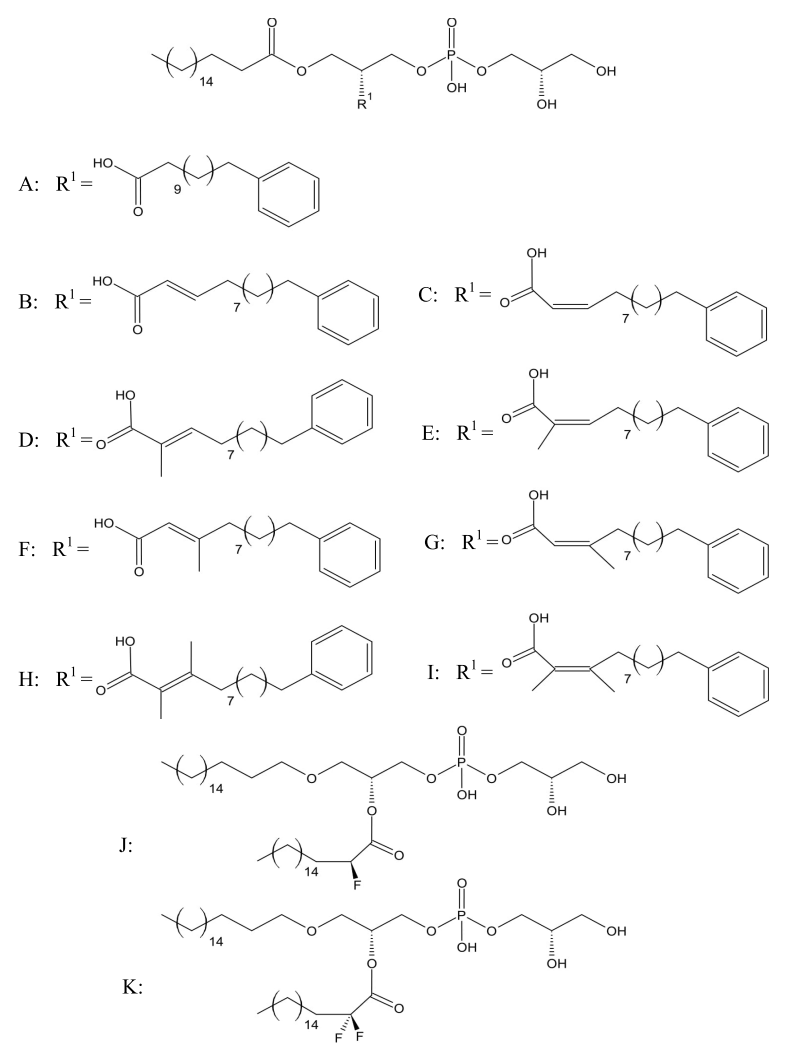

Figure 1. Chemical structures of the phospholipids. (A) Saturated, (B) (E)-unsaturated, (C) (Z)-unsaturated, (D) (E)- $\alpha$-methyl, (E) (Z)- $\alpha$-methyl, (F) (E)- $\beta$-methyl, (G) (Z)- $\beta$-methyl, (H) (E)- $\alpha, \beta$ dimethyl, (I) (Z)- $\alpha, \beta$-dimethyl, (J) $\alpha$-fluoro, and (K) $\alpha, \alpha$-difluoro.

which form hydrophobic walls to restrict the water-molecule path.

\section{METHODS}

Molecular Dynamics Simulations. Molecular dynamics simulations and energy minimization were carried out using the software NAMD version 2.8. ${ }^{34} \mathrm{MD}$ simulations were performed on the crystal structure of human secretory phospholipase $\mathrm{A}_{2}$-IIA (hsPLA $\mathrm{AIIA}_{2}$; hereafter, referred to as $\mathrm{SPLA}_{2}$-IIA) that was downloaded from the Protein Data Bank (PDB entry code $1 \mathrm{KQU}){ }^{35}$ The structure was solved in complex with the inhibitor 6-phenyl-4(R)-(7-phenyl-heptanoylamino)-hexanoic acid and resolved to $2.1 \AA \AA^{6,36}$ To construct the Michaelis-Menten complexes of the different lipids, the inhibitor was replaced with a transition-state analogue taken from the crystal structure of European Honeybee (Apis mellifera) venom phospholipase $\mathrm{A}_{2}$ complexed with the transition-state analogue 1-O-octyl-2-heptylphosphonyl-sn-glycero-3-phosphoethanol-amine $\left[\operatorname{diC}_{8}(2 \mathrm{Ph}) \mathrm{PE}\right]$ and solved to $2.1 \AA$ (PDB entry code: 1 POC) ${ }^{37}$ To place the transition-state analogue in the binding pocket of $\mathrm{sPLA}_{2}$-IIA, $1 \mathrm{KQU}$ and 1 POC structures were aligned followed by deleting all entries in 1POC besides the transition analogue, deleting the inhibitor in $1 \mathrm{KQU}$ and keeping the two calcium ions and water molecules in $1 \mathrm{KQU}$. The structures for the different ester phospholipids (Figure 1) were built from diC8(2Ph) PE using SPARTAN version 1.0.2 (Wavefunction Inc., Irvine, California). The modified ester lipids were placed in the sPLA $\mathrm{P}_{2}$-IIA structure by aligning the modified phospholipids with $\operatorname{diC} 8(2 \mathrm{Ph}) \mathrm{PE}$ in the $\mathrm{SPLA}_{2}$-IIA-diC8(2Ph)PE structure 
followed by deleting $\operatorname{diC} 8(2 \mathrm{Ph}) \mathrm{PE}$; the initial distances between relevant residues in the Michaelis-Menten complex are listed in Table S1 (Supporting Information). The CHARMM27 all-hydrogen parameter set with the TIP3P flexible water model $^{38}$ was applied throughout all the simulations. Missing force field parameters for the ester molecules were taken from similar atom types in the CHARMM $27^{39}$ force field and the CHARMM35 ether force field. ${ }^{40}$ The transferability of parameters has previously been proven successful for similar systems, where simulation results showed good agreement with experimental data. ${ }^{29,30,41,42}$ The structures were solvated using the graphical program Visualization Molecular Dynamics, VMD, ${ }^{43}$ utilizing the plug-in program Solvate. ${ }^{44}$ To neutralize the systems, 18 randomly chosen water molecules were replaced with chloride ions. The final systems contained $\sim 4900$ water molecules, and the simulation cell dimensions were approximately $55 \times 50 \times 70$ $\AA^{3}$. Each sPLA ${ }_{2}$-IIA-ester lipid complex was initially energyminimized for 1000 steps using the conjugate gradient algorithm within NAMD. ${ }^{34}$ During the minimization, only the ester lipid and residues within $15 \AA$ of the ligand were relaxed. This step was followed by additional minimizations, where all atoms were relaxed, and different minimization steps (i.e., 100, 125, 150, 175, and 200 steps) were used to obtain five different starting conditions for each simulation of a particular sPLA 2 -IIA-ester lipid complex that would allow accessing the statistical uncertainties in the simulation results. The simulations were started by heating the systems to $T=$ $300 \mathrm{~K}$ within 100 ps using the NPT (constant number of atoms, $N$, constant pressure, $P$, and constant temperature, $T$ ) ensemble and a time step of $1 \mathrm{fs}$. This was followed by the production run of $10 \mathrm{~ns}$ in the NPT ensemble. As demonstrated in previous studies, sampling of $10 \mathrm{~ns}$ simulations provided results that were in good agreement with experimental data. ${ }^{30}$ The isotropic pressure was set to 1 atm and kept constant using the Langevin piston method ${ }^{45}$ with a damping coefficient, piston period, and decay of $5 \mathrm{ps}^{-1}$, $200 \mathrm{fs}$, and $500 \mathrm{fs}$, respectively. The electrostatic forces were calculated using the particle mesh Ewald method ${ }^{46,47}$ with a grid spacing of approximately $1.0 \AA$ and a fourth-order spline for the interpolation. The long-ranged part of the electrostatic forces was evaluated every fourth fs. Van der Waals interactions were cut off at $12 \AA$ in combination with a switching function starting at $10 \AA$. Periodic boundary conditions were applied in all three Cartesian directions. Analyses of the trajectories were performed using $\mathrm{VMD}^{43}$ along with in-house Tcl-scripts. A summary of the phospholipid names, abbreviations, and the number of simulations is provided in Table 1.

Analysis of $\mathrm{SPLA}_{2}$-IIA Water Intake. The catalytic machinery for the hydrolyzation of phospholipids by $\mathrm{sPLA}_{2}$ IIA consists of $\mathrm{His}^{47}$ and $\mathrm{Asp}^{91}$, a calcium ion that works as a cofactor, and a water molecule that acts as a nucleophile. ${ }^{36,48}$ The first step of the catalysis is the formation of a MichaelisMenten complex between the enzyme and the phospholipid. The Michaelis-Menten complex is stabilized by the calcium ion, which coordinates with the backbone oxygen of $\mathrm{Gly}^{29}$, the two carboxylate oxygens of $\mathrm{Asp}^{48}$, the carbonyl oxygen positioned in the sn-2 chain, and a phosphorous oxygen of the phospholipid, as shown in Figure 2. The carbonyl carbon in the sn-2 chain is attacked by a nucleophilic water molecule, and $\mathrm{His}^{47}$ abstracts the leftover proton from the attacking nucleophile, where the positively charged imidazole ring is stabilized by Asp $^{91}$. Asp ${ }^{91}$ makes hydrogen bonds with both
Table 1. Summary of the Phospholipid Names, Abbreviations, and the Number of MD Simulations Performed

\begin{tabular}{|c|c|c|}
\hline name & abbreviation $^{a}$ & $\begin{array}{l}\text { number of } \\
\text { simulations }\end{array}$ \\
\hline $\begin{array}{l}\text { 1-stearoyl-2-(12-phenyldodecanoyl)-sn-glycero- } \\
\text { 3-phospho-(S)-glycerol }\end{array}$ & saturated & 5 \\
\hline $\begin{array}{l}\text { 1-stearoyl-2-((E)-12-phenyldodec-2-enoyl)-sn- } \\
\text { glycero-3-phospho-(S)-glycerol }\end{array}$ & $\begin{array}{l}(E)- \\
\text { unsaturated }\end{array}$ & 5 \\
\hline $\begin{array}{l}\text { 1-stearoyl-2-((Z)-12-phenyldodec-2-enoyl)-sn- } \\
\text { glycero-3-phospho-(S)-glycerol }\end{array}$ & $\begin{array}{l}(Z)- \\
\text { unsaturated }\end{array}$ & 5 \\
\hline $\begin{array}{l}\text { 1-stearoyl-2-((E)-2-methyl-12-phenyldodec-2- } \\
\text { enoyl)-sn-glycero-3-phospho-(S)-glycerol }\end{array}$ & $(E)$ - $\alpha$-methyl & 5 \\
\hline $\begin{array}{l}\text { 1-stearoyl-2-((Z)-2-methyl-12-phenyldodec-2- } \\
\text { enoyl)-sn-glycero-3-phospho-( } S) \text {-glycerol }\end{array}$ & (Z)- $\alpha$-methyl & 5 \\
\hline $\begin{array}{l}\text { 1-stearoyl-2-((E)-3-methyl-12-phenyldodec-2- } \\
\text { enoyl)-sn-glycero-3-phospho-( } S) \text {-glycerol }\end{array}$ & $(E)-\beta$-methyl & 5 \\
\hline $\begin{array}{l}\text { 1-stearoyl-1-((Z)-3-methyl-12-phenyldodec-2- } \\
\text { enoyl)-sn-glycero-3-phospho-( } S) \text {-glycerol }\end{array}$ & $(Z)-\beta$-methyl & 5 \\
\hline $\begin{array}{l}\text { 1-stearoyl-2-((E)-2,3-dimethyl-12- } \\
\text { phenyldodec-2-enoyl)-sn-glycero-3-phospho- } \\
(S) \text {-glycerol }\end{array}$ & $\begin{array}{l}(E)-\alpha, \beta- \\
\text { dimethyl }\end{array}$ & 5 \\
\hline $\begin{array}{l}\text { 1-stearoyl-2-((Z)-2,3-dimethyl-12- } \\
\text { phenyldodec-2-enoyl)-sn-glycero-3-phospho- } \\
(S) \text {-glycerol }\end{array}$ & $\begin{array}{l}(Z)-\alpha, \beta- \\
\text { dimethyl }\end{array}$ & 5 \\
\hline $\begin{array}{l}\text { 1-O-octadecyl-2-(2-fluorooctadecanoyl)-sn- } \\
\text { glycero-3-phospho- }(S) \text {-glycerol }\end{array}$ & $\alpha$-fluoro & 5 \\
\hline $\begin{array}{l}\text { 1-O-octadecyl-2-(2,2-difluorooctadecanoyl)-sn- } \\
\text { glycero-3-phospho-(S)-glycerol }\end{array}$ & $\alpha, \alpha$-difluoro & 10 \\
\hline
\end{tabular}

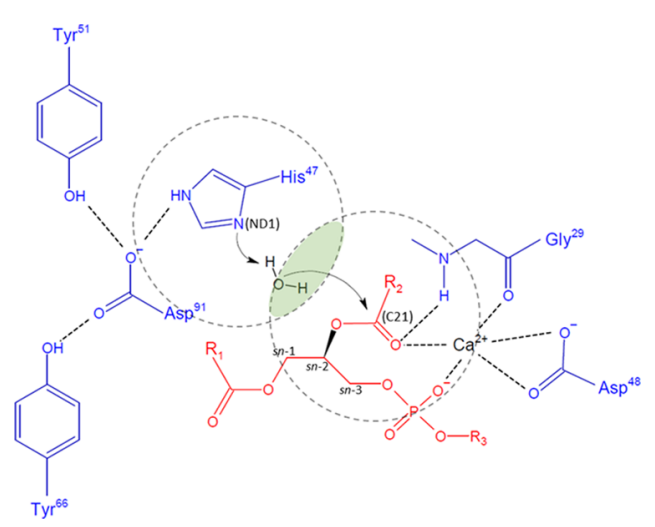

Figure 2. Schematic representation of the catalytic mechanism of sPLA $_{2}$-IIA and the Michaelis-Menten complex. The blue structures represent residues in $\mathrm{SPLA}_{2}$-IIA, while the red one represents the phospholipid. The dashed circles centered at either $\mathrm{His}^{47}(\mathrm{ND} 1)$ or $\mathrm{S}(\mathrm{C} 21)$ generate the overlap that represents the $\mathrm{H}-\mathrm{S}$ region (shown in green). Atom types specified in parentheses refer to the Protein Data Bank (PDB) nomenclature.

$\mathrm{Tyr}^{51}$ and $\mathrm{Tyr}^{66}$. The last step of the catalytic reaction is the collapse of the transition state, where a proton from $\mathrm{His}^{47}$ protonates the sn- 2 oxygen, which generates the free fatty acid and the lysophospholipid. ${ }^{36,49}$ The water molecule must be positioned correctly for the nucleophilic attack, i.e., the water molecule must be in close vicinity of both the nitrogen of $\mathrm{His}^{47}$ $\left[\left(\mathrm{His}^{47}(\mathrm{ND} 1)\right)\right]$ and the carbonyl carbon of the phospholipid $[S(C 21)]$. Atom types specified in parentheses refer to the Protein Data Bank (PDB) nomenclature. The region between $\mathrm{S}(\mathrm{C} 21)$ and $\mathrm{His}^{47}(\mathrm{ND} 1)$ generated by the overlap of two circles with centers at $\mathrm{His}^{47}(\mathrm{ND} 1)$ and $\mathrm{S}(\mathrm{C} 21)$ will from here on be defined as the $\mathrm{H}-\mathrm{S}$ region, which is shown in green in Figure 2. 
The data from the MD simulations of the phospholipid$\mathrm{sPLA}_{2}$ complexes were analyzed using AQUA-DUCT (version $0.5 .14) .{ }^{32}$ In the analysis, the water molecules were traced to determine their paths during the simulations. The "object", which states the area of interest, was defined as the $\mathrm{H}-\mathrm{S}$ region and is seen in Figure 3A. Different radii of the circles going

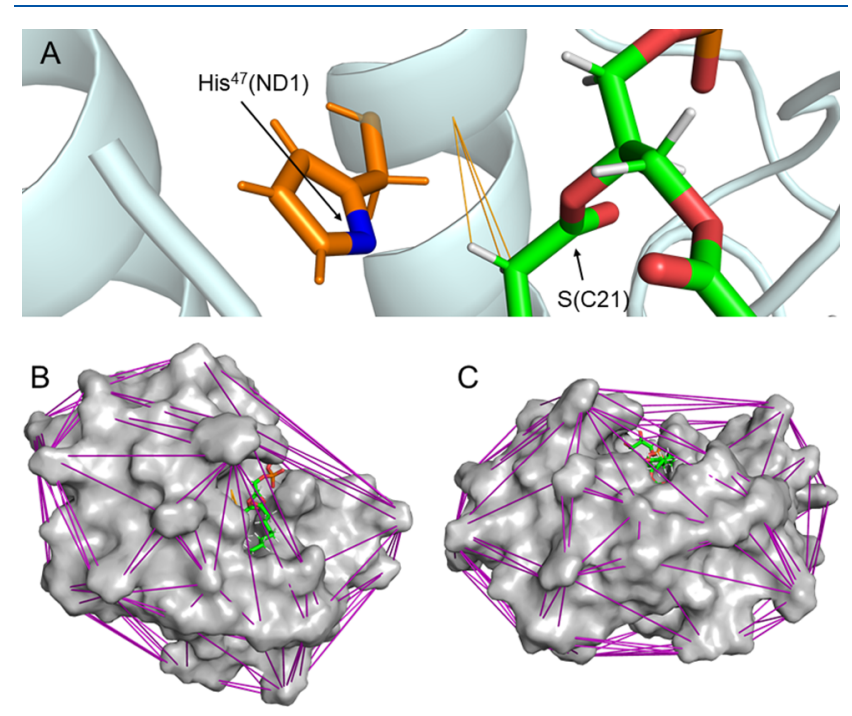

Figure 3. First frame of the MD simulation of the natural substrate-

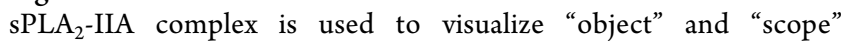
boundaries using AQUA-DUCT. The visualization is made with regard to $(\mathrm{A})$ object area $[\mathrm{H}-\mathrm{S}$ region $(3.5 \AA)]$. The object area is shown as orange lines. $(\mathrm{B}, \mathrm{C}) \mathrm{Scope}$ is marked by purple lines and is a rough approximation of the solvent-excluded molecular surface. The surface of $s \mathrm{PLA}_{2}$-IIA is shown in gray. Note that $\mathrm{SPLA}_{2}$-IIA is defined as the scope and not the phospholipid-enzyme complex. PyMOL (version 2.2.0) was used for the three-dimensional representation of structures.

from 3.0 to $6.5 \AA$ with $0.5 \AA$ intervals were tested to see the effect of varying the size of the $\mathrm{H}-\mathrm{S}$ region on water intake. For simplicity, an abbreviation is introduced such that the radii of the circles are mentioned after the $\mathrm{H}-\mathrm{S}$ region; for example, when the radii of the circles are $3.5 \AA$, the abbreviation will be "H-S region $(3.5 \AA)$ )". The "scope", which specifies the area in which the water molecules should be traced, was defined as a convex hull of sPLA ${ }_{2}$-IIA and was calculated for every frame; see Figure 3B,C. The convex hull method is a rough approximation of the solvent-excluded-surface (i.e., the surface of the macromolecule complex), and the method is based on the quickhull algorithm. ${ }^{32,50}$ The convex hull method was used to ensure that the traced water molecules were inside the phospholipid-sPLA $\mathrm{A}_{2}$ complex. Clustering of the pathways was done using the barber method, ${ }^{51}$ and clusters containing two or fewer inlets were defined as outliers. Inlets mark the positions where traced water molecules enter or leave the scope. Reclustering of outliers was performed using the dbscan method. ${ }^{52}$ Paths shorter than two frames were discarded.

It is assumed that the activity of $\mathrm{SPLA}_{2}$ is correlated to the amount of water molecules that reaches the active site of $\mathrm{sPLA}_{2}$, i.e., the water intake. To compare the water intakes for the different phospholipid-sPLA 2 complexes, the water intakes were normalized using a reference point. This was done since motions of water molecules are determined by their thermal energy and are stochastic in nature, which leads to a significant variation in the results. The reference point used was the water intakes determined when the circles had radii of $6.0 \AA$ for the individual phospholipid-sPLA $\mathrm{A}_{2}$ complexes. The averages and standard deviations of the water intakes (i.e., number of water molecules) for the different complexes were calculated using the normalized water counts for a series of MD simulations of each complex.

Multiple Sequence Alignment. A multiple sequence alignment was made to find conserved residues in $\mathrm{SPLA}_{2}$-IIA since these residues could play an important role in the enzyme water intake and hence the activity of the enzyme. A total of 97 different $\mathrm{sPLA}_{2}$ sequences were included in the alignment (Figure S1, Supporting Information); among those are five of the subtype IIA, five of the subtype IID, six of the subtype IIE, one of the subtype IIF, and ten of the subtype X. The sequences were obtained from the NCBI database (http:// blast.ncbi.nlm.nih.gov/). The sequences were aligned using EMBL-EBI online tool Multiple Alignment using Fast Fourier Transform (MAFFT, version 7.39). ${ }^{53}$ The alignment was generated using the BLOSUM $62^{54}$ matrix with default settings for a gap-opening penalty of 1.53 and a gap-extension penalty of 0.123 . The resulting alignment was visualized using the online tool ESPript (http://espript.ibcp.fr, version 3.0). ${ }^{55}$

Analysis of Catalytic Water-Molecule Pathways to the Active Site. The catalytic water molecules found in the analysis of $\mathrm{sPLA}_{2}$ water intake were further analyzed using

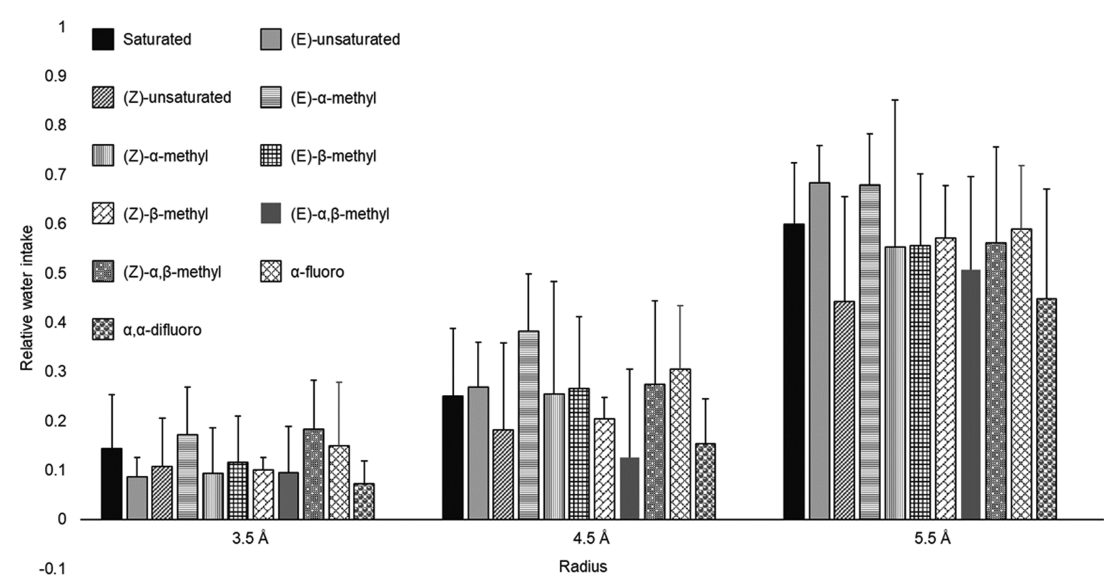

Figure 4. Relative water intakes for the phospholipid-sPLA $\mathrm{A}_{2}$ complexes. The water intakes are normalized with respect to the water intakes determined when the radii of the circles centered at $\mathrm{His}^{47}$ (ND1) and $\mathrm{S}(\mathrm{C} 21)$ were $6.0 \AA$. 
AQUA-DUCT. A water molecule was defined as catalytic when the molecule reached the $\mathrm{H}-\mathrm{S}$ region $(3.5 \AA)$, as defined in previous studies. ${ }^{56,57}$ The same settings were used as in the analysis of $\mathrm{sPLA}_{2}$ water intake but with an additional requirement that the water molecules had to be less than 3.5 $\AA$ away from $\mathrm{Phe}^{5}$ or $\mathrm{Tyr}^{51}$ in $\mathrm{sPLA}_{2}$-IIA to be counted; these residues were hypothesized to be crucial for the enzyme activity, since they are conserved in the different sPLA variants, as seen in the multiple sequence alignment (Figure S1, Supporting Information). The number of catalytic water molecules that came close to either $\mathrm{Phe}^{5}$ or $\mathrm{Tyr}^{51}$ was normalized with respect to the total number of catalytic water molecules for a particular complex. The averages and standard deviations for the complexes were calculated from the normalized water counts from a series of MD simulations of each complex.

\section{RESULTS}

A series of $\mathrm{MD}$ simulations of the different phospholipidsPLA 2 complexes were performed. The simulations were started with different initial conditions, which were obtained by varying the number of minimization steps. The MD simulations and analysis of the results were done to (i) identify the water intake of the different phospholipid-sPLA complexes, (ii) determine the importance of the conserved residues $\mathrm{Phe}^{5}$ and $\mathrm{Tyr}^{51}$ in the water intake, and (iii) monitor key distances in the Michaelis-Menten complexes for the different phospholipid analogue-sPLA ${ }_{2}$ complexes.

Water Intake of SPLA 2 -IIA. The ability of water molecules to enter $\mathrm{SPLA}_{2}$ and reach the $\mathrm{H}-\mathrm{S}$ region $(3.5 \AA)$ can be affected by the structure of the phospholipid bound to the enzyme. Figure 4 and Table 2 summarize the results from the analysis of the relative water intakes for the different phospholipid-enzyme complexes. When the $\mathrm{H}-\mathrm{S}$ region is made narrower, i.e., by decreasing the radii of the circles (Figure 2), fewer water molecules reach the $\mathrm{H}-\mathrm{S}$ region. This is especially clear for the saturated substrate; only $17 \%$ of the

Table 2. Relative Water Intakes for the PhospholipidsPLA $_{2}$ Complexes $^{a}$

\begin{tabular}{|c|c|c|c|}
\hline \multicolumn{4}{|c|}{ relative water intake } \\
\hline & $\begin{array}{c}3.5 \AA \\
\left(\text { mean } \pm \mathrm{SD}^{b}\right)\end{array}$ & $\begin{array}{c}4.5 \AA \\
\left(\text { mean } \pm \mathrm{SD}^{b}\right)\end{array}$ & $\begin{array}{c}5.5 \AA \\
\left(\text { mean } \pm \mathrm{SD}^{b}\right)\end{array}$ \\
\hline saturated & $0.1 \pm 0.1$ & $0.3 \pm 0.1$ & $0.6 \pm 0.1$ \\
\hline $\begin{array}{l}(E)- \\
\text { unsaturated }\end{array}$ & $0.09 \pm 0.04$ & $0.27 \pm 0.09$ & $0.68 \pm 0.08$ \\
\hline $\begin{array}{l}(Z)- \\
\text { unsaturated }\end{array}$ & $0.1 \pm 0.1$ & $0.2 \pm 0.2$ & $0.4 \pm 0.2$ \\
\hline (E)- $\alpha$-methyl & $0.2 \pm 0.1$ & $0.4 \pm 0.1$ & $0.7 \pm 0.1$ \\
\hline (Z)- $\alpha$-methyl & $0.09 \pm 0.09$ & $0.3 \pm 0.2$ & $0.6 \pm 0.3$ \\
\hline (E)- $\beta$-methyl & $0.12 \pm 0.09$ & $0.3 \pm 0.1$ & $0.6 \pm 0.1$ \\
\hline$(Z)$ - $\beta$-methyl & $0.10 \pm 0.03$ & $0.20 \pm 0.4$ & $0.6 \pm 0.1$ \\
\hline $\begin{array}{l}\text { (E)- } \alpha, \beta- \\
\text { dimethyl }\end{array}$ & $0.09 \pm 0.09$ & $0.1 \pm 0.2$ & $0.5 \pm 0.2$ \\
\hline $\begin{array}{l}(Z)-\alpha, \beta- \\
\text { dimethyl }\end{array}$ & $0.2 \pm 0.1$ & $0.3 \pm 0.2$ & $0.6 \pm 0.2$ \\
\hline$\alpha$-fluoro & $0.1 \pm 0.1$ & $0.3 \pm 0.2$ & $0.6 \pm 0.2$ \\
\hline$\alpha, \alpha$-difluoro & $0.07 \pm 0.04$ & $0.2 \pm 0.09$ & $0.4 \pm 0.2$ \\
\hline
\end{tabular}

${ }^{a}$ The averages (Means) and standard deviations(SDs) were determined for a series of simulations of each phospholipid-sPLA2 complex. ${ }^{b}$ Standard deviations were calculated using the formula $\mathrm{SD}=\sqrt{\frac{\sum(x-\bar{x})^{2}}{(n-1)}}$. amount of water, which reaches the region when the radii are $5.5 \AA$, reaches the region when the radii are $3.5 \AA$. This phenomenon is expected, since the narrower the $\mathrm{H}-\mathrm{S}$ region becomes, the deeper the water molecules must travel into the enzyme to reach the $\mathrm{H}-\mathrm{S}$ region. It can be seen from the results that the saturated, $(E)$ - $\alpha$-methyl, (Z)- $\alpha, \beta$-methyl, and $\alpha$-fluoro are the lipids with the highest water intake, while $(E)$ unsaturated, (Z)- $\alpha$-methyl, and $\alpha, \alpha$-difluoro have the lowest ones. The lower amount of catalytic water molecules reaching the $\mathrm{H}-\mathrm{S}$ region $(3.5 \AA)$ of $(E)$-unsaturated, $(Z)$ - $\alpha$-methyl, and $\alpha, \alpha$-difluoro may be caused by the structural differences close to the sn- $2^{\text {seb }}$ position, which could be sterically blocking the water-molecule pathway.

Multiple Sequence Alignment. A total of 97 sequences were included in the multiple sequence alignment of $\mathrm{sPLA}_{2}$ (Figure S1, Supporting Information) to determine conserved residues that could be important for the activity and water intake of the phospholipid-enzyme complex. The 14 cysteine residues in human $\mathrm{SPLA}_{2}$-IIA are conserved across all of the variants of the enzyme. The cysteine residues are part of seven disulfide bridges that contribute to the stabilization of the protein tertiary structure. $\mathrm{Gly}^{29}, \mathrm{His}^{47}, \mathrm{Asp}^{48}, \mathrm{Tyr}^{51}, \mathrm{Tyr}^{66}$, and Asp ${ }^{91}$ are all part of the Michaelis-Menten complex, which is formed during $\mathrm{SPLA}_{2}$-IIA catalysis of phospholipids, as seen in Figure 2. These residues are highly conserved in the different sPLA ${ }_{2}$-IIA variants, indicating that the residues could be important for the activity and water intake. $\mathrm{Gly}^{29}, \mathrm{His}^{47}, \mathrm{Tyr}^{51}$, and $\mathrm{Asp}^{91}$ are conserved across all of the 97 variants, while $\mathrm{Tyr}^{51}$ and $\mathrm{Tyr}^{66}$ are conserved in all but one of the variants. The alignment shows that $\mathrm{Phe}^{5}$ is conserved in 77 of the 97 sequences and that it is conserved in all of the sPLA -IIE variants. It has previously been proposed that $\mathrm{Phe}^{5}$ could be an important residue for the water-intake mechanism, ${ }^{58}$ but the importance of $\mathrm{Phe}^{5}$ in SPLA$_{2}$-IIA water intake cannot be confirmed by the multiple sequence alignment alone. We therefore have investigated the water-intake path to the active site, and the results are presented in the following section.

Water Pathway to the Active Site. For sPLA 2 -IIA to hydrolyze phospholipids, a water molecule must reach the active site and be positioned correctly for the nucleophilic attack on the carbonyl carbon in the sn-2 chain of the phospholipid. As mentioned in the Methods section, a water molecule is categorized as catalytic when it reaches the $\mathrm{H}-\mathrm{S}$ region $(3.5 \AA)$. Multiple sequence alignment demonstrates that both $\mathrm{Phe}^{5}$ and $\mathrm{Tyr}^{51}$ were highly conserved across the different sPLA $_{2}$-IIA species, suggesting that these residues are of particular interest. This is further supported by the results of the pathway analysis made using AQUA-DUCT. The analysis was done for the saturated substrate, (E)- $\alpha$-methyl, (Z)- $\beta$ methyl, $\alpha$-fluoro, and $\alpha, \alpha$-difluoro phospholipids, and the results show that the two conserved residues $\mathrm{Phe}^{5}$ and $\mathrm{Tyr}^{51}$ both play an important role in guiding the catalytic water molecules to the $\mathrm{H}-\mathrm{S}$ region $(3.5 \AA)$, as seen in Figure 5. All catalytic water molecules pass within $3.5 \AA$ of $\mathrm{Phe}^{5}$ or $\mathrm{Tyr}^{51}$ in all of the phospholipid-enzyme complexes.

Most of the catalytic water molecules show proximity to both $\mathrm{Phe}^{5}$ and $\mathrm{Tyr}^{51}$ on their way to the $\mathrm{H}-\mathrm{S}$ region $(3.5 \AA)$ and not just to one of them. A visual analysis of the results was performed, as can be seen in Figure 6, which is representative of all of the phospholipid-sPLA $\mathrm{P}_{2}$-IIA complexes. The visual analysis corresponds to the pathway analysis results shown in Figure 5. The results indicate that the aromatic side chains of $\mathrm{Phe}^{5}$ and $\mathrm{Tyr}^{51}$ direct the catalytic water molecules into the 


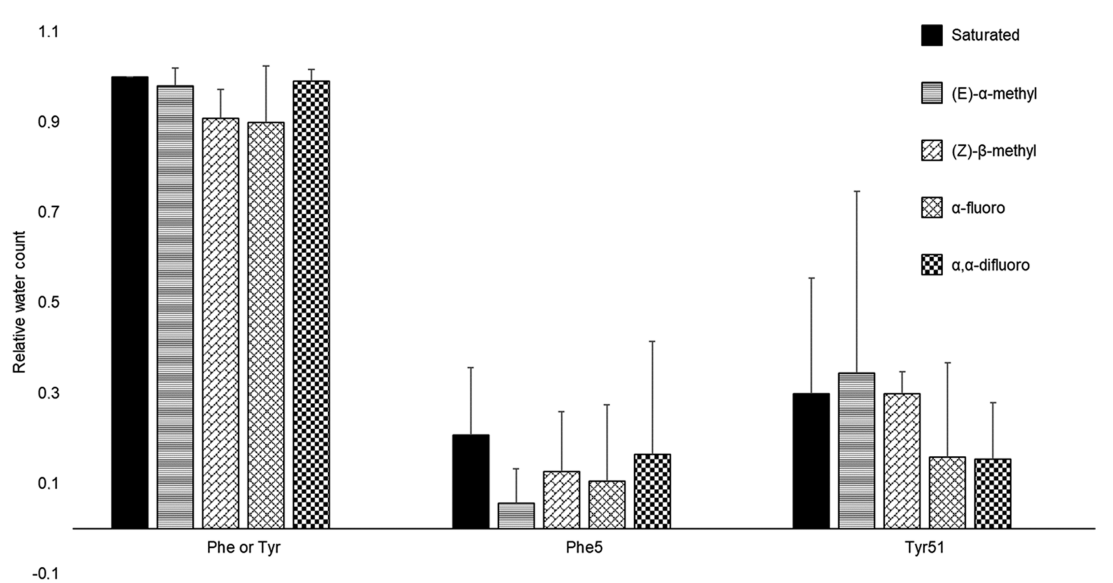

Figure 5. Relative water intake for the catalytic water-molecule paths into the active site of six different phospholipid-sPLA ${ }_{2}$ complexes. "Phe ${ }^{5}$ or $\mathrm{Tyr}^{51}$ " represents the relative water intake of catalytic water molecules whose paths came into contact with either Phe ${ }^{5}$ or Tyr ${ }^{51}$. "Phe ${ }^{5 "}$ represents the relative water intake of catalytic water molecules that only came into contact with $\mathrm{Phe}^{5}$ and not with $\mathrm{Tyr}^{51}$. "Tyr ${ }^{51}$ " represents the relative water intake of catalytic water molecules that only came into contact with $\mathrm{Tyr}^{51}$ and not with $\mathrm{Phe}^{5}$. The results were arbitrarily normalized with respect to the water intake determined for the individual complexes for the $\mathrm{H}-\mathrm{S}$ region $(6.0 \AA)$.

correct position for the nucleophilic attack. Not only does the catalytic water molecules enter sPLA 2 -IIA through the same hydrophobic cleft, but also they leave the core of the enzyme the same way as they enter (see Figure 6E). It was expected that the water molecules had to leave the core, since classical MD simulations do not allow for bond breakage and formation. Unlike Mitusińska et al., ${ }^{59}$ who identified rarely detected paths to the active site of Solanum tuberosum epoxide hydrolase, tracking the water molecules using AQUA-DUCT, we did not identify rare water paths but observed that all of the catalytic water molecules leave the active site the same way as they entered, indicating that the active site can only be accessed by a single hydrophobic cleft. The hydrophobic cleft that the catalytic water molecules use, also called the active-site cleft, $^{58}$ is formed by $\mathrm{Phe}^{5}, \mathrm{Tyr}^{51}, \mathrm{Tyr}^{66}$, and $\mathrm{Asp}^{91}$ (Figure 7). The catalytic water molecules also pass by close to the surfaceexposed residues Asn ${ }^{1}, \mathrm{Leu}^{2}, \mathrm{Thr}^{61}$, and $\mathrm{Lys}^{62}$, where $\mathrm{Thr}^{61}$ and $\mathrm{Lys}^{62}$ are conserved in all of the $\mathrm{SPLA}_{2}$-IIA variants (Figure 8). This suggests that these residues form the entry point of water molecules into the active-site cleft of the sPLA $\mathrm{PL}_{2}$-IIA variants.

Distance between $\mathrm{His}^{47}$ (ND1) and S(C21). Besides the analysis of the catalytic water-molecule path using AQUADUCT, the average distance between the atoms $\mathrm{His}^{47}$ (ND1) and $\mathrm{S}(\mathrm{C} 21)$ was also determined for the phospholipid-sPLA complexes. This was done to see how the different phospholipids would affect the structural integrity of the Michaelis-Menten complex formed during hydrolysis. The mean and standard deviations for 11 phospholipids were calculated based on the last $5 \mathrm{~ns}$ from a series of different MD simulations that were performed on each phospholipid-sPLA complex (Figure 9). For hydrolysis to occur, at least two conditions must be fulfilled. First, water molecules need to reach the catalytic site, and second, the geometry of the Michaelis-Menten complex must be maintained for the hydrolysis to succeed. The saturated phospholipid resembles the natural substrate of $\mathrm{SPLA}_{2}$-IIA, and hence, it is expected that SPLA $_{2}$-IIA is active toward the saturated phospholipid. Using this requirement, sPLA ${ }_{2}$-IIA should also be able to hydrolyze the $(E)$-unsaturated, $(Z)$-unsaturated, $(E)$ - $\beta$-methyl, $(Z)$ - $\beta$-methyl, and $(Z)-\alpha, \beta$-dimethyl phospholipids, since their average distances lie close to the average distance present in the saturated phospholipid-sPLA 2 -IIA complex (Figure 9).
On the other hand, sPLA -IIA might show less activity toward the (E)- $\alpha$-methyl, (Z)- $\alpha$-methyl, (E)- $\alpha, \beta$-dimethyl, $\alpha$-fluoro, and $\alpha, \alpha$-difluoro, since their $\mathrm{His}^{47}(\mathrm{ND} 1)-\mathrm{S}(\mathrm{C} 21)$ distances are larger than the distance observed in the saturated phospholipid-sPLA 2 -IIA complex.

\section{DISCUSSION}

sPLA ${ }_{2}$-IIA Activity toward Phospholipids. The activity of sPLA $\mathrm{PL}_{2}$-IIA toward different phospholipids is proportional to the amount of water molecules that reach the active site of the enzyme-phospholipid complex. ${ }^{56,57}$ For a water molecule to participate in the catalytic reaction, it has to reach the $\mathrm{H}-\mathrm{S}$ region (3.5 $\AA$ ); see Figure 2 . The relative water intake at the $\mathrm{H}-\mathrm{S}$ region $(3.5 \AA)$ is in the range of $0.07-0.2$ (Table 2 ). Using the relative water intake of 0.1 (determined for the natural, saturated substrate-sPLA - IIA complex) as a threshold, sPLA ${ }_{2}$-IIA complexes with (E)- $\alpha$-methyl (mean: 0.2 ) and $(Z)-\alpha, \beta$-dimethyl $(0.2)$ result in the highest relative water intake among the tested phospholipids. Similar relative waterintake values are seen for the remaining phospholipid analogues corresponding to the value determined for the natural substrate. Experimentally, it has been shown that some of the phospholipids are substrates of sPLA $_{2}$-IIA when constituted in mixed-composition liposomes. ${ }^{31}$ Viart performed hydrolysis experiments to quantify substrate depletion and product formation using MALDI-TOF-MS and HPLC. The results showed that $\mathrm{SPLA}_{2}$-IIA has a high activity toward the saturated and $(E)$-unsaturated phospholipids, a medium activity toward the $(Z)$-unsaturated phospholipid, a low activity toward $(Z)-\alpha$-methyl and $(Z)-\beta$-methyl, and no activity toward (E)- $\alpha$-methyl and (E)- $\beta$-methyl. ${ }^{31}$ From these experimental results, it is clear that the probability of water molecules reaching the $\mathrm{H}-\mathrm{S}$ region $(3.5 \AA)$ alone is not a sufficient criterion to rank the phospholipids according to the ability of sPLA2-IIA to hydrolyze the different phospholipids due to the statistical uncertainties in the relative water intake (Table 2). It is plausible that quantifying the number of water molecules in the $\mathrm{H}-\mathrm{S}$ region and the water-intake paths alone are insufficient in efficiently approximating the activity of the different phospholipid-sPLA 2 complexes due to the relatively minor structural differences among substrates studied here. 


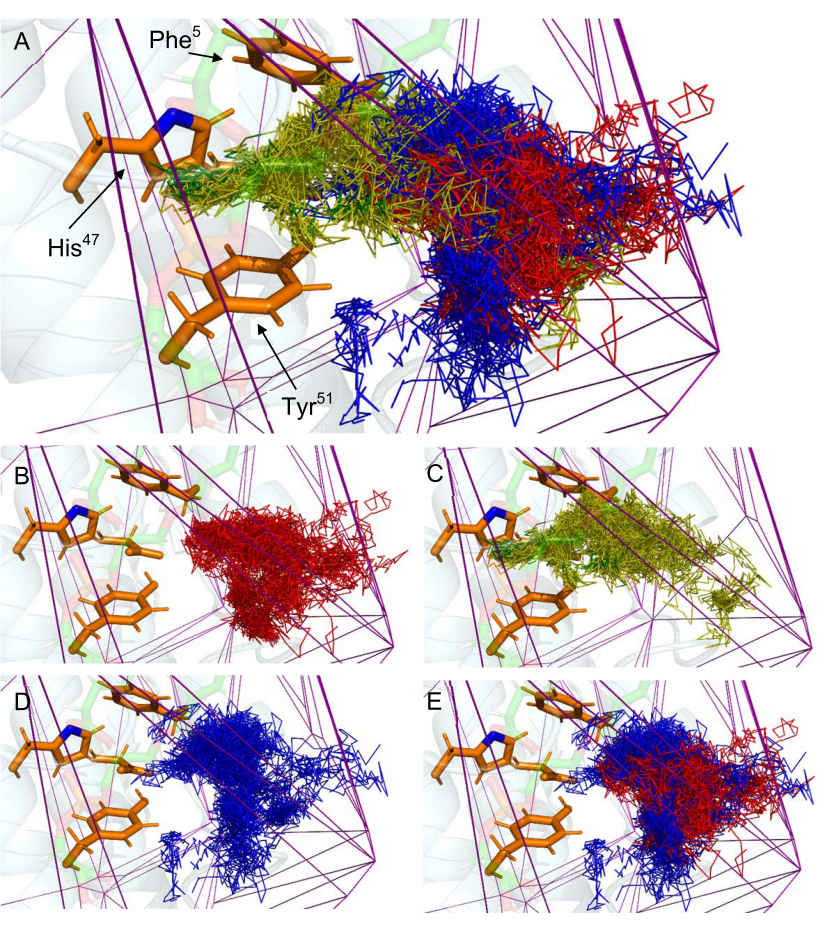

Figure 6. Catalytic water-molecule paths to the active site of the saturated substrate-sPLA 2 -IIA complex guided by the aromatic residues $\mathrm{Phe}^{5}$ and $\mathrm{Tyr}^{51}$, shown as orange-colored sticks $\left[\mathrm{His}^{47}(\mathrm{ND} 1)\right.$ shown in blue]. For the visualization of the molecule and the "scope", the first frame of the simulation was used. The choice of color is standard AQUA-DUCT coloring; incoming paths of water molecules are shown in red, object parts are shown in yellow and green, outgoing paths of water molecules are shown in blue, and the scope boundaries are displayed in purple and correspond to the boundaries shown in Figure 3. (A) All catalytic water-molecule paths. (B) Incoming paths that begin where a water molecule enters the scope and end where the water molecule for the first time enters the $\mathrm{H}-\mathrm{S}$ region $(3.5 \AA)$. (C) Object parts of paths. Green-colored paths mark positions where the water molecule was strictly inside the $\mathrm{H}-\mathrm{S}$ region $(3.5 \AA)$. Yellow-green paths indicate positions where the water molecule was inside the scope but not inside the $\mathrm{H}-\mathrm{S}$ region $(3.5 \AA)$. (D) Outgoing paths that begin where a water molecule leaves the $\mathrm{H}-$ $S$ region $(3.5 \AA)$ and end when the water molecule leaves the scope. (E) Incoming and outgoing paths. The reason why the incoming and outgoing path starting and ending points are not closer to the $\mathrm{H}-\mathrm{S}$ region $(3.5 \AA)$ is that only the first frame of the simulation is visualized. The molecule is not static during the simulation, so neither is the $\mathrm{H}-\mathrm{S}$ region $(3.5 \AA)$.

An important second criterion is that key distances in the Michaelis-Menten complex should be maintained such that hydrolysis can occur. The distances in the Michaelis-Menten complex should be close to the distances seen in the saturated substrate-sPLA 2 -IIA complex, since the saturated substrate represents the natural substrate for the enzyme, and it is known that SPLA $_{2}$-IIA has a high affinity toward the natural substrate. ${ }^{31}$ The probability of water molecules reaching the $\mathrm{H}-\mathrm{S}$ region $(3.5 \AA)$ in the different phospholipid-sPLA 2 -IIA complexes in combination with maintaining key distances in the Michaelis-Menten complexes agrees well with experimental results of the ability of sPLA - IIA to degrade liposomes composed of some of the phospholipids studied here. ${ }^{31}$ The saturated, $(E)$-unsaturated, $(Z)$-unsaturated, and $(Z)-\beta$-methyl

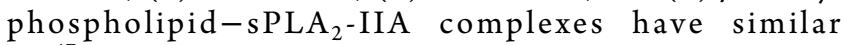
$\mathrm{His}^{47}(\mathrm{ND} 1)-\mathrm{S}(\mathrm{C} 21)$ distances in the Michaelis-Menten complex, providing the geometry for catalysis. These findings

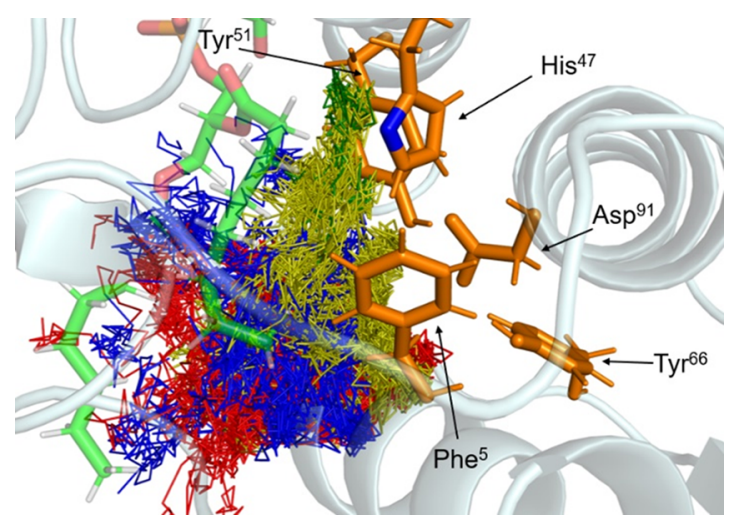

Figure 7. Top views of $\mathrm{PLA}_{2}$-IIA. Residues in the active-site cleft are represented as orange-colored sticks, while the catalytic watermolecule path to the active site is colored using default AQUADUCT coloring; see Figure 6 for details.

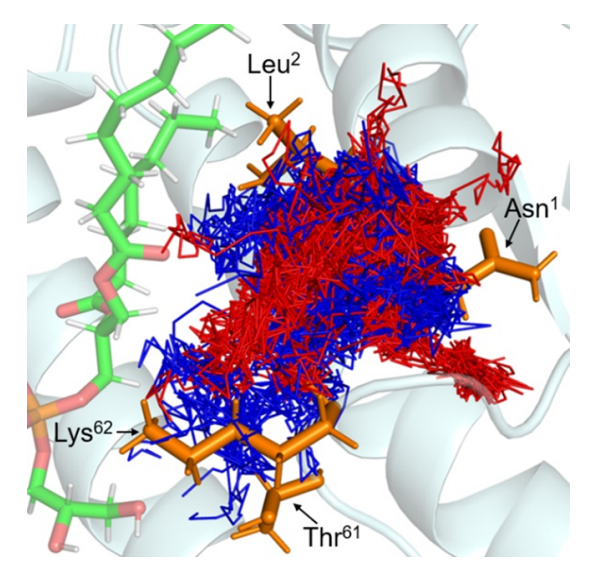

Figure 8. Surface-exposed residues, which often come into contact with catalytic water molecules. The surface-exposed residues are presented as orange-colored sticks, while the catalytic water-molecule path to the active site is colored using default AQUA-DUCT coloring; see Figure 6 for details.

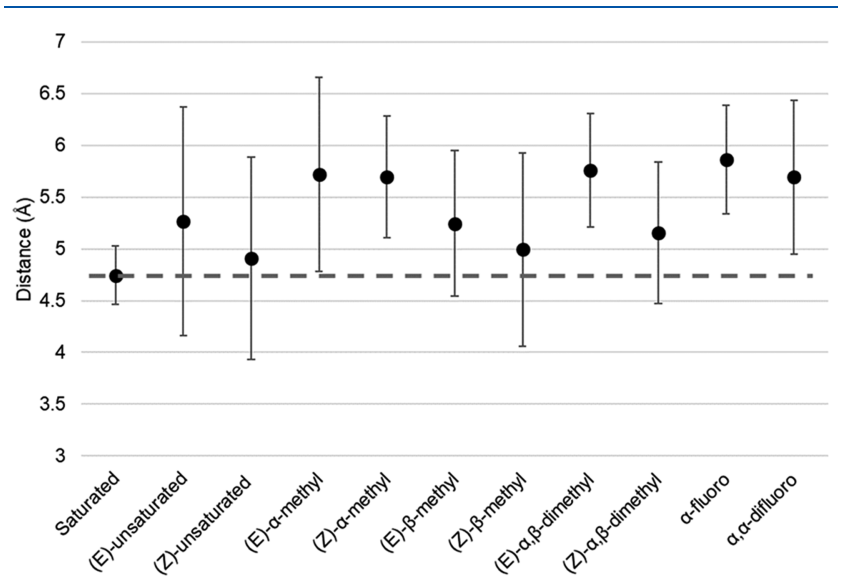

Figure 9. Average distances between $\mathrm{His}^{47}(\mathrm{ND} 1)$ and $\mathrm{S}(\mathrm{C} 21)$ for the 11 different phospholipid-sPLA 2 -IIA complexes. The distances were calculated from the last $5 \mathrm{~ns}$ of the MD simulations. A series of independent simulations of each phospholipid-sPLA 2 -IIA complex was used to calculate the means and corresponding standard deviations. The dashed line represents the mean distance for the saturated substrate. 
are consistent with experimental results, showing that these phospholipids are substrates for $\mathrm{sPLA}_{2}$. Furthermore, $(E)-\alpha$ methyl and (Z)- $\alpha$-methyl both have average $\mathrm{His}^{47}$ (ND1)$S(C 21)$ distances that are larger than the distance found for the saturated-sPLA - IIA complex, which agrees with their experimentally determined lower activity. The hydrolysis experiments showed that (E)- $\beta$-methyl could not be hydrolyzed by SPLA $_{2}$-IIA. This correlates well with the simulations, where the key distance between $\mathrm{His}^{47}$ (atom: ND1) and the substrate (C21) is larger than the distance observed for the saturated substrate even when considering the relatively high uncertainty. To the best of our knowledge, no experimental data is available for (Z)- $\alpha, \beta$-dimethyl, (E)- $\alpha, \beta$-dimethyl, $\alpha$ fluoro, and $\alpha, \alpha$-difluoro. However, taking the distances in the Michaelis-Menten complexes and their uncertainties into account, the enzyme should exhibit very low or no activity toward these phospholipid analogues. However, monitoring the distances between key residues in the Michaelis-Menten complex does not provide information about the energy barrier of the enzymatic reaction along the reaction coordinate and can, therefore, not stand alone in the search for possible substrates. Determining the energy barrier along the reaction coordinate requires $\mathrm{QM} / \mathrm{MM}$ calculations, as has previously been performed on sPLA $_{2}$-IIA-substrate complexes. ${ }^{42,60}$

Role of $\mathrm{Phe}^{5}$ and $\mathrm{Tyr}^{51}$. From the multiple sequence alignment of 97 different $\mathrm{SPLA}_{2}$ sequences, it is seen that $\mathrm{His}^{47}$, $\mathrm{Asp}^{48}, \mathrm{Tyr}^{51}$, and $\mathrm{Asp}^{91}$ are highly conserved residues. The above-mentioned residues are all within $5 \AA$ of the active site of sPLA 2 -IIA and are shown in Figure 10. The incoming catalytic

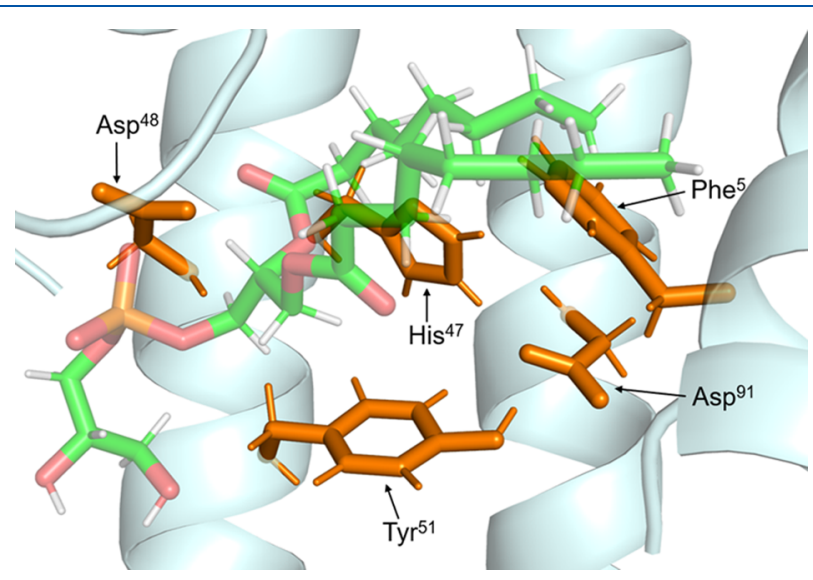

Figure 10. Highly conserved residues in sPLA $\mathrm{PL}_{2}$ IIA in complex with the saturated substrate. Highly conserved residues are displayed as orange-colored sticks. The saturated substrate is displayed as sticks and colored green. $\mathrm{PLA}_{2}$-IIA is shown as a cartoon in pale blue. Most of the highly conserved residues also participate in the catalytic machinery.

water molecules are in frequent contact with $\mathrm{Phe}^{5}, \mathrm{Tyr}^{51}$, and $\mathrm{Asp}^{91}$ in their path to the active site. Other residues in $\mathrm{SPLA}_{2}$ are also highly conserved, as seen in the alignment, but they do not seem to play an important role in the hydrolysis reaction of phospholipids. As seen in Figure 5, all catalytic water molecules come into close contact with either $\mathrm{Phe}^{5}$ or $\mathrm{Tyr}^{51}$, and the majority of the catalytic water molecules encounter both of the residues, which indicates that they both play an important part in guiding the water molecules toward the active site. In particular, $\mathrm{Phe}^{5}$ and $\mathrm{Tyr}^{51}$ form aromatic walls that direct the catalytic water molecule into the correct position so that it can act as a nucleophile and attack the sn-2 carbonyl carbon of the phospholipids. The nature of the interactions between the water molecules and the aromatic residues has not been analyzed in this study, but Jain et al. have presented the importance of the lone-pair $-\pi$ interactions between water oxygen electrons and the aromatic centers of the aromatic residues. ${ }^{61}$ Both the statistical and AQUA-DUCT results obtained in this study are consistent with mutational studies of $\mathrm{Phe}^{5}$ and $\mathrm{Tyr}^{51}{ }^{62,63} \mathrm{Phe}^{5}$ has been mutated to Val, Trp, and Tyr, and the effects of the mutations were studied by analyzing the conformational stability using circular dichroism spectroscopy and ${ }^{1} \mathrm{H}$ NMR. ${ }^{62}$ When Phe ${ }^{5}$ is mutated to a hydrophilic or a nonaromatic hydrophobic residue, the activity level of sPLA $_{2}$ decreased more than 200 -fold, ${ }^{62}$ suggesting that due to the absence of the aromatic wall, the flow of water molecules into the $\mathrm{H}-\mathrm{S}$ region $(3.5 \AA)$ is disturbed. In another study, $\mathrm{Tyr}^{51}$ was mutated to Lys, Phe, and $\mathrm{Val}$ and the conformational stability and activity of the mutated enzyme were characterized using monomeric, micellar, and bilayer forms of substrates together with circular dichroism spectroscopy. ${ }^{63}$ The mutational studies showed that the aromaticity of $\mathrm{Phe}^{5}$ and $\mathrm{Tyr}^{51}$ is important for the stability and activity of SPLA $_{2}$-IIA. ${ }^{63}$ When $\mathrm{Tyr}^{51}$ was mutated to phenylalanine, the enzyme stability was reduced, but the activity of the enzyme was the same, which might be because the aromatic walls were still present. ${ }^{63}$

The catalytic water molecules do not pass by only $\mathrm{Phe}^{5}$ and $\mathrm{Tyr}^{51}$ on their way to the active site of $\mathrm{SPLA}_{2}$-IIA. Most of the catalytic water molecules also encounter Asp ${ }^{91}$. This can be seen from the AQUA-DUCT analysis of the saturated substrate-sPLA 2 complex in Figure 7. Besides $\mathrm{Phe}^{5}, \mathrm{Tyr}^{51}$, and $\mathrm{Asp}^{91}$, the water molecules also come into contact with $\mathrm{Tyr}^{66}$, and these four residues form the lining of the active-site cleft that funnels catalytic water molecules into the $\mathrm{H}-\mathrm{S}$ region. As mentioned in the Results section and highlighted in Figure 6 , the catalytic water molecules use the same path on their way in and out of the catalytic site. The path traced by the water molecules comes close to the surface-exposed residues $\mathrm{Asn}^{1}$, Leu ${ }^{2}, \mathrm{Thr}^{61}$, and $\mathrm{Lys}^{62}$, as seen in Figure $8 .^{36,64}$ Noticeably, $\mathrm{Leu}^{2}, \mathrm{Thr}^{61}$, and $\mathrm{Lys}^{62}$ are highly conserved in different $\mathrm{SPLA}_{2}$-IIA species (Figure S1, Supporting Information).

\section{CONCLUSIONS}

The statistical and visual analyses of 11 different phospholipid-sPLA 2 -IIA complexes using AQUA-DUCT provide an understanding of the enzyme activity dependency on the water intake and on the water-intake mechanism. The phospholipids differed from one another; some of the phospholipids had one or two methyl groups introduced close to the scissile sn-2 ester bond $\left(\mathrm{sn}-2^{\mathrm{seb}}\right)$, some had fluorine atoms added, while others were unsaturated. The structure of the phospholipids affected the water intake. The introduction of a methyl group at the $\alpha$ or $\beta$ position in the $(Z)$-conformation reduced the water intake drastically. The same is seen if two fluorine atoms are introduced close to $\mathrm{sn}-2^{\mathrm{seb}}$. On the other hand, introducing a methyl group at either the $\alpha$ or $\beta$ position in the $(E)$ conformation only reduced the water intake marginally compared to the saturated (natural) substrate. The same effect is seen when only one fluorine atom is introduced. These results emphasize that phospholipids used in making liposomes must have a structure that does not hinder the water intake if enzymatic hydrolysis is to take place. Our study clearly demonstrates that all catalytic water molecules reaching the 
active site of sPLA - -IIA are guided into the correct position by the two aromatic residues $\mathrm{Phe}^{5}$ and $\mathrm{Tyr}^{51}$, which are conserved across several sPLA ${ }_{2}$-IIA variants. Furthermore, water molecules come in close contact with the surface-exposed residues $\mathrm{Asn}^{1}, \mathrm{Leu}^{2}, \mathrm{Thr}^{61}$, and $\mathrm{Lys}^{62}$, where the latter three residues are

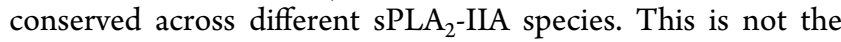
case for only the saturated substrate-sPLA ${ }_{2}$ complex; the same trend is also seen for phospholipids with a methyl group introduced close to $\mathrm{sn}-2^{\text {seb }}$ and for polarized phospholipids where a fluorine atom is introduced. The obtained results are in good agreement with experimental results, which investigated the ability of sPLA 2 -IIA to hydrolyze liposomes made of different phospholipids studied here. The results suggest that the computational approach presented here can be used as a screening method for assessing potential substrates for sPLA 2 -IIA by monitoring the water intake to the $\mathrm{H}-\mathrm{S}$ region and key distances in the Michaelis-Menten complex.

\section{ASSOCIATED CONTENT}

\section{SI Supporting Information}

The Supporting Information is available free of charge at https://pubs.acs.org/doi/10.1021/acs.jpcb.9b10837.

Initial distances between relevant residues in the Michaelis-Menten complex; sequence alignment using EMBL-EBI online tool multiple alignment using Fast Fourier Transform (MAFFT, version 7.39) (PDF)

\section{AUTHOR INFORMATION}

\section{Corresponding Author}

Günther H. J. Peters - Department of Chemistry, Technical University of Denmark, DK-2800 Kgs. Lyngby, Denmark; 이이.org/0000-0001-9754-2663; Email: ghp@ kemi.dtu.dk

\section{Authors}

Helena D. Tjørnelund - Department of Chemistry, Technical University of Denmark, DK-2800 Kgs. Lyngby, Denmark; (1) orcid.org/0000-0001-8648-3266

Jesper J. Madsen - Department of Global Health, College of Public Health, University of South Florida, Tampa, Florida 33620, United States; orcid.org/0000-0003-1411-9080

Complete contact information is available at:

https://pubs.acs.org/10.1021/acs.jpcb.9b10837

\section{Notes}

The authors declare no competing financial interest.

\section{ACKNOWLEDGMENTS}

The authors are grateful to the AQUA-DUCT team for helpful discussions regarding the AQUA-DUCT results. The simulations were carried out at the high-performance cluster at the Technical University of Denmark.

\section{REFERENCES}

(1) Leistad, L.; Feuerherm, A. J.; Ostensen, M.; Faxvaag, A.; Johansen, B. Presence of Secretory Group IIa and V Phospholipase $\mathrm{A}(2)$ and Cytosolic Group IV Alpha Phospholipase A(2) in Chondrocytes from Patients with Rheumatoid Arthritis. Clin. Chem. Lab. Med. 2004, 42, 602-610.

(2) Leidy, C.; Mouritsen, O. G.; Jørgensen, K.; Peters, G. H. Evolution of Lipid Membrane Morphology and Organization during Phospholipase A(2) Hydrolysis Studied by Time-Resolved AFM. Biophys. J. 2004, 87, 408-418.
(3) Peters, G. H.; Leidy, C.; Kaasgaard, T.; Mouritsen, O. G.; Jørgensen, K. Investigation of Lipid Membrane Organization, Morphology, and Dynamics by Atomic Force Microscopy of Supported Bilayers. Recent Res. Dev. Biophys. 2004, 3, 163-185.

(4) Six, D. A.; Dennis, E. A. The Expanding Superfamily of Phospholipase A(2) Enzymes: Classification and Characterization. Biochim. Biophys. Acta 2000, 1488, 1-19.

(5) White, S. P.; Scott, D. L.; Otwinowski, Z.; Gelb, M. H.; Sigler, P. B. Crystal-Structure of Cobra-Venom Phospholipase-A2 in Complex with a Transitions-State Analog. Science 1990, 250, 1560-1563.

(6) Scott, D. L.; Otwinowski, Z.; Gelb, M. H.; Sigler, P. B. CrystalStructure of Bee-Venom Phospholipase-A2 in Complex with a Transition-State Analog. Science 1990, 250, 1563-1566.

(7) Dennis, E. A. Diversity of Group Types, Regulation, and Function of Phospholipase A2. J. Biol. Chem. 1994, 269, 1305713060 .

(8) Heinrikson, R. L.; Krueger, E. T.; Keim, P. S. Amino Acid Sequence of Phospholipase A2-Alpha from the Venom of Crotalus Adamanteus. A New Classification of Phospholipases A2 Based upon Structural Determinants. J. Biol. Chem. 1997, 252, 4913-4921.

(9) Davidson, F. F.; Dennis, E. A. Evolutionary Relationships and Implications for the Regulation of Phospholipase A2 from Snake Venom to Human Secreted Forms. J. Mol. Evol. 1990, 31, 228-238.

(10) Quach, N. D.; Arnold, R. D.; Cummings, B. S. Secretory Phospholipase A2 Enzymes as Pharmacological Targets for Treatment of Disease. Biochem. Pharmacol. 2014, 90, 338-348.

(11) Yarla, N.; Bishayee, A.; Vadlakonda, L.; Chintala, R.; Duddukuri, G.; Reddanna, P.; Dowluru, K. Phospholipase A2 Isoforms as Novel Targets for Prevention and Treatment of Inflammatory and Oncologic Diseases. Curr. Drug Targets 2016, 17, $1940-1962$

(12) Valentin, E.; Lambeau, G. Increasing Molecular Diversity of Secreted Phospholipases A(2) and Their Receptors and Binding Proteins. Biochim. Biophys. Acta 2000, 1488, 59-70.

(13) Bezzine, S.; Bollinger, J. G.; Singer, A. G.; Veatch, S. L.; Keller, S. L.; Gelb, M. H. On the Binding Preference of Human Groups IIA and X Phospholipases A 2 for Membranes with Anionic Phospholipids. J. Biol. Chem. 2002, 277, 48523-48534.

(14) Buckland, A. G.; Heeley, E. L.; Wilton, D. C. Bacterial Cell Membrane Hydrolysis by Secreted Phospholipases A(2): A Major Physiological Role of Human Group IIa SPLA(2) Involving Both Bacterial Cell Wall Penetration and Interfacial Catalysis. Biochim. Biophys. Acta 2000, 1484, 195-206.

(15) Laye, J. P.; Gill, J. H. Phospholipase A(2) Expression in Tumours: A Target for Therapeutic Intervention? Drug Discovery Today 2003, 8, 710-716.

(16) Bezzine, S.; Koduri, R. S.; Valentin, E.; Murakami, M.; Kudo, I.; Ghomashchi, F.; Sadilek, M.; Lambeau, G.; Gelb, M. H. Exogenously Added Human Group X Secreted Phospholipase A2 but Not the Group IB, IIA, and V Enzymes Efficiently Release Arachidonic Acid from Adherent Mammalian Cells. J. Biol. Chem. 2000, 275, 31793191.

(17) Enomoto, A.; Murakami, M.; Valentin, E.; et al. Redundant and Segregated Functions of Granule-Associated Heparin-Binding Group II Subfamily of Secretory Phospholipases A(2) in the Regulation of Degranulation and Prostaglandin D-2 Synthesis in Mast Cells. J. Immunol. 2000, 165, 4007-4014.

(18) Buckland, A. G.; Wilton, D. C. Anionic Phospholipids, Interfacial Binding and the Regulation of Cell Functions. Biochim. Biophys. Acta 2000, 1483, 199-216.

(19) Han, S. K.; Yoon, E. T.; Scott, D. L.; Sigler, P. B.; Cho, W. Structural Aspects of Interfacial Adsorption. J. Biol. Chem. 1997, 272, $3573-3582$.

(20) Leidy, C.; Linderoth, L.; Andresen, T. L.; Mouritsen, O. G.; Jørgensen, K.; Peters, G. H. Domain-Induced Activation of Human Phospholipase A2 Type IIA: Local versus Global Lipid Composition. Biophys. J. 2006, 90, 3165-3175.

(21) Yamashita, S.; Yamashita, J.-I.; Ogawa, M. Overexpression of Group II Phospholipase A2 in Human Breast Cancer Tissues Is 
Closely Associated with Their Malignant Potency. Br. J. Cancer 1994, 69, 1166-1170.

(22) Sved, P.; Scott, K. F.; McLeod, D.; King, N. J. C.; Singh, J.; Tsatralis, T.; Nikolov, B.; Boulas, J.; Nallan, L.; Gelb, M. H.; et al. Oncogenic Action of Secreted Phospholipase A2 in Prostate Cancer. Cancer Res. 2004, 64, 6934-6940.

(23) Jiang, J. Z.; Neubauer, B. L.; Graff, J. R.; Chedid, M.; Thomas, J. E.; Roehm, N. W.; Zhang, S. B.; Eckert, G. J.; Koch, M. O.; Eble, J. N.; et al. Expression of Group IIA Secretory Phospholipase A2 Is Elevated in Prostatic Intraepithelial Neoplasia and Adenocarcinoma. Am. J. Pathol. 2002, 160, 667-671.

(24) Ilsley, J. N. M.; Nakanishi, M.; Flynn, C.; Belinsky, G. S.; De Guise, S.; Adib, J. N.; Dobrowsky, R. T.; Bonventre, J. V.; Rosenberg, D. W. Cytoplasmic Phospholipase A 2 Deletion Enhances Colon Tumorigenesis. Cancer Res. 2005, 65, 2636-2643.

(25) Ohmachi, H.; Egami, H.; Murata, K.; Akagi, J.; Ohshima, S.; Kiyohara, H.; Kurizaki, T.; Yamamoto, S.; Shibata, Y.; Ogawa, M. Biological Significance of the Production of Membrane-Associated Phospholipase A2 in Human Gastric Cancer. Int. Congr. Ser. 2003, $1255,361-366$.

(26) Andresen, T. L.; Jensen, S. S.; Jørgensen, K. Advanced Strategies in Liposomal Cancer Therapy: Problems and Prospects of Active and Tumor Specific Drug Release. Prog. Lipid Res. 2005, 44, 68-97.

(27) Andresen, T.; Jensen, S.; Kaasgaard, T.; Jorgensen, K. Triggered Activation and Release of Liposomal Prodrugs and Drugs in Cancer Tissue by Secretory Phospholipase A2. Curr. Drug Delivery 2005, 2, 353-362.

(28) Mihelich, E. D.; Schevitz, R. W. Structure-Based Design of a New Class of Anti-Inflammatory Drugs: Secretory Phospholipase A2 Inhibitors, SPI. Biochim. Biophys. Acta 1999, 1441, 223-228.

(29) Peters, G. H.; Møller, M. S.; Jørgensen, K.; Rönnholm, P.; Mikkelsen, M.; Andresen, T. L. Secretory Phospholipase A 2 Hydrolysis of Phospholipid Analogues Is Dependent on Water Accessibility to the Active Site. J. Am. Chem. Soc. 2007, 129, 54515461.

(30) Linderoth, L.; Andresen, T. L.; Jørgensen, K.; Madsen, R.; Peters, G. H. Molecular Basis of Phospholipase A2 Activity toward Phospholipids with Sn-1 Substitutions. Biophys. J. 2008, 94, 14-26.

(31) Viart, H. Organic Synthesis - Applications in Enzymatic Studies, Catalysis and Surface Modification. Ph.D. Dissertation, Department of Chemistry, Technical University of Denmark, 2013.

(32) Magdziarz, T.; Mitusińska, K.; Gołdowska, S.; Płuciennik, A.; Stolarczyk, M.; Ługowska, M.; Góra, A. AQUA-DUCT: A Ligands Tracking Tool. Bioinformatics 2017, 33, 2045-2046.

(33) Subramanian, K.; Góra, A.; Spruijt, R.; Mitusińska, K.; SuarezDiez, M.; Martins dos Santos, V.; Schaap, P. J. Modulating D-Amino Acid Oxidase (DAAO) Substrate Specificity through Facilitated Solvent Access. PLoS One 2018, 13, No. e0198990.

(34) Kalé, L.; Skeel, R.; Bhandarkar, M.; Brunner, R.; Gursoy, A.; Krawetz, N.; Phillips, J.; Shinozaki, A.; Varadarajan, K.; Schulten, K. NAMD2: Greater Scalability for Parallel Molecular Dynamics. J. Comput. Phys. 1999, 151, 283-312.

(35) Bernstein, F. C.; Koetzle, T. F.; Williams, G. J. B.; Meyer, E. F.; Brice, M. D.; Rodgers, J. R.; Kennard, O.; Shimanouchi, T.; Tasumi, M. The Protein Data Bank: A Computer-Based Archival File for Macromolecular Structures. J. Mol. Biol. 1977, 112, 535-542.

(36) Scott, D. L.; White, S.; Otwinowski, Z.; Yuan, W.; Gelb, M.; Sigler, P. Interfacial Catalysis: The Mechanism of Phospholipase A2. Science 1990, 250, 1541-1546.

(37) Hansford, K. A.; Reid, R. C.; Clark, C. I.; Tyndall, J. D. A.; Whitehouse, M. W.; Guthrie, T.; McGeary, R. P.; Schafer, K.; Martin, J. L.; Fairlie, D. P. D-Tyrosine as a Chiral Precusor to Potent Inhibitors of Human Nonpancreatic Secretory Phospholipase A2 (IIa) with Antiinflammatory Activity. ChemBioChem 2003, 4, 181-185.

(38) Jorgensen, W. L.; Chandrasekhar, J.; Madura, J. D.; Impey, R. W.; Klein, M. L. Comparison of Simple Potential Functions for Simulating Liquid Water. J. Chem. Phys. 1983, 79, 926-935.
(39) MacKerell, A. D.; Banavali, N.; Foloppe, N. Development and Current Status of the CHARMM Force Field for Nucleic Acids. Biopolymers 2000, 56, 257-265.

(40) Vorobyov, I.; Anisimov, V. M.; Greene, S.; Venable, R. M.; Moser, A.; Pastor, R. W.; MacKerell, A. D. Additive and Classical Drude Polarizable Force Fields for Linear and Cyclic Ethers. J. Chem. Theory Comput. 2007, 3, 1120-1133.

(41) Linderoth, L.; Peters, G. H.; Jørgensen, K.; Madsen, R.; Andresen, T. L. Synthesis of Sn-1 Functionalized Phospholipids as Substrates for Secretory Phospholipase A2. Chem. Phys. Lipids 2007, 146, 54-66.

(42) Linderoth, L.; Fristrup, P.; Hansen, M.; Melander, F.; Madsen, R.; Andresen, T. L.; Peters, G. H. Mechanistic Study of the SPLA 2 -Mediated Hydrolysis of a Thio-Ester Pro Anticancer Ether Lipid. J. Am. Chem. Soc. 2009, 131, 12193-12200.

(43) Humphrey, W.; Dalke, A.; Schulten, K. VMD - Visual Molecular Dynamics. J. Mol. Graphics 1996, 14, 33-38.

(44) Grubmuller, H. SOLVATE. Solvate: A Program to Create Atomic Solvent Models.Max Planck Institute, 1996.

(45) Feller, S. E.; Zhang, Y.; Pastor, R. W.; Brooks, B. R. Constant Pressure Molecular Dynamics Simulation: The Langevin Piston Method. J. Chem. Phys. 1995, 103, 4613-4621.

(46) Darden, T.; York, D.; Pedersen, L. Particle Mesh Ewald: An N . $\log (\mathrm{N})$ Method for Ewald Sums in Large Systems. J. Chem. Phys. 1993, 98, 10089-10092.

(47) Essmann, U.; Perera, L.; Berkowitz, M. L.; Darden, T.; Lee, H.; Pedersen, L. G. A Smooth Particle Mesh Ewald Method. J. Chem. Phys. 1995, 103, 8577-8593.

(48) Janssen, M. J. W.; van de Wiel, W. A. E. C.; Beiboer, S. H. W.; van Kampen, M. D.; Verheij, H. M.; Slotboom, A. J.; Egmond, M. R. Catalytic Role of the Active Site Histidine of Porcine Pancreatic Phospholipase A2 Probed by the Variants H48Q, H48N and H48K. Protein Eng. Des. Select. 1999, 12, 497-503.

(49) Scott, D. L.; Sigler, P. B. Structure and Catalytic Mechanism of Secretory Phospholipases A-2. Adv. Protein Chem. 1994, 45, 53-88.

(50) Barber, C. B.; Dobkin, D. P.; Huhdanpaa, H. The Quickhull Algorithm for Convex Hulls. ACM Trans. Math. Softw. 1996, 22, $469-483$.

(51) Magdziarz, T.; Mitusińska, K.; Raczyńska, A.; Góra, A. AquaDuct Documentation - Release, version 0.5.9. 2018.

(52) Ester, M.; Kriegel, H. P.; Sander, J.; Xu, X. In A Density-Based Algorithm for Discovering Clusters in Large Spatial Databases with Noise, Proceedings of the 2nd International Conference on Knowledge Discovery and Data Mining, 1996; pp 226-231.

(53) Squizzato, S.; Park, Y. M.; Buso, N.; Gur, T.; Cowley, A.; Li, W.; Uludag, M.; Pundir, S.; Cham, J. A.; McWilliam, H.; et al. The EBI Search Engine: Providing Search and Retrieval Functionality for Biological Data from EMBL-EBI. Nucleic Acids Res. 2015, 43, W585W588.

(54) Henikoff, S.; Henikoff, J. G. Amino Acid Substitution Matrices from Protein Blocks. Proc. Natl. Acad. Sci. U.S.A. 1992, 89, 1091510919.

(55) Robert, X.; Gouet, P. Deciphering Key Features in Protein Structures with the New ENDscript Server. Nucleic Acids Res. 2014, 42, W320-W324.

(56) Wedberg, R.; Abildskov, J.; Peters, G. H. Protein Dynamics in Organic Media at Varying Water Activity Studied by Molecular Dynamics Simulation. J. Phys. Chem. B 2012, 116, 2575-2585.

(57) Rudas, T.; Schröder, C.; Boresch, S.; Steinhauser, O. Simulation Studies of the Protein-Water Interface. II. Properties at the Mesoscopic Resolution. J. Chem. Phys. 2006, 124, No. 234908.

(58) Madsen, J. J.; Linderoth, L.; Subramanian, A. K.; Andresen, T. L.; Peters, G. H. Secretory Phospholipase A 2 Activity toward Diverse Substrates. J. Phys. Chem. B 2011, 115, 6853-6861.

(59) Mitusińska, K.; Magdziarz, T.; Bzówka, M.; Stańczak, A.; Gora, A. Exploring Solanum Tuberosum Epoxide Hydrolase Internal Architecture by Water Molecules Tracking. Biomolecules 2018, 8, No. 143. 
(60) Madsen, J. J.; Fristrup, P.; Peters, G. H. Theoretical Assessment of Fluorinated Phospholipids in the Design of Liposomal DrugDelivery Systems. J. Phys. Chem. B 2016, 120, 9661-9671.

(61) Jain, A.; Ramanathan, V.; Sankararamakrishnan, R. Lone Pair $\cdots \pi$ Interactions between Water Oxygens and Aromatic Residues: Quantum Chemical Studies Based on High-Resolution Protein Structures and Model Compounds. Protein Sci. 2009, 18, 595-605.

(62) Liu, X.; Zhu, H.; Huang, B.; Rogers, J.; Yu, B.-Z.; Kumar, A.; Jain, M. K.; Sundaralingam, M.; Tsai, M.-D. Phospholipase A2 Engineering. Probing the Structural and Functional Roles of NTerminal Residues with Site-Directed Mutagenesis, $x$-Ray, and NMR. Biochemistry 1995, 34, 7322-7334.

(63) Dupureur, C. M.; Yu, B. Z.; Jain, M. K.; Noel, J. P.; Deng, T.; Li, Y.; Byeon, I. J. L.; Tsai, M. D. Phospholipase A2 Engineering. Structural and Functional Roles of Highly Conserved Active Site Residues Tyrosine-52 and Tyrosine-73. Biochemistry 1992, 31, 64026413.

(64) Sekar, K.; Yu, B.-Z.; Rogers, J.; Lutton, J.; Liu, X.; Chen, X.; Tsai, M.-D.; Jain, M. K.; Sundaralingam, M. Phospholipase A 2 Engineering. Structural and Functional Roles of the Highly Conserved Active Site Residue Aspartate-99. Biochemistry 1997, 36, 3104-3114. 